\title{
Interpretation of trauma radiographs by junior doctors in accident and emergency departments: a cause for concern?
}

\author{
C A J McLauchlan, K Jones, H R Guly
}

\begin{abstract}
Objectives-To investigate how well junior doctors in accident and emergency (A\&E) were able to diagnose significant $x$ ray abnormalities after trauma and to compare their results with those of more senior doctors.

Methods-49 junior doctors (senior house officers) in A\&E were tested with an $x$ ray quiz in a standard way. Their results were compared with 34 consultants and senior registrars in $A \& E$ and radiology, who were tested in the same way. The quiz included $30 x$ rays (including 10 normal films) that had been taken after trauma. The abnormal films all had clinically significant, if sometimes uncommon, diagnoses. The results were compared and analysed statistically.
\end{abstract}

Results-The mean score for the abnormal $x$ rays for all the junior doctors was only $32 \%$ correct. The 10 junior doctors with more experience scored significantly better $(P<0.001)$ but their mean score was only $48 \%$. The mean score of the senior doctors was $80 \%$, which was significantly higher than the juniors $(P<0.0001)$.

Conclusions-The majority of junior doctors misdiagnosed significant trauma abnormalities on $x$ ray. Senior doctors scored well, but were not infallible. This suggests that junior doctors are not safe to work on their own in A\&E departments. There are implications for training, supervision, and staffing in $A \& E$ departments, as well as a need for fail-safe mechanisms to ensure adequate patient care and to improve risk management. (F Accid Emerg Med 1997;14:295-298) eter (Wonford) Hospital, Exeter, UK C A J McLauchlan

Frenchay Hospital, Bristol, UK

K Jones

Derriford Hospital, Plymouth, UK H R Guly

Correspondence to: Chris A J McLauchlan, Consultant/Director of Accident and Emergency Department, Royal Devon and Exeter (Wonford) Hospital, Exeter EX2 5DW, UK.

Accepted for publication 7 May 1997 routine practice. ${ }^{2}$ Previous studies have shown that between about $2 \%$ and $8 \%$ of all $x$ rays are misdiagnosed in A\&E departments ${ }^{34}$ but some of these are false positives and many of the missed injuries are insignificant.

If false positives are excluded, significant misdiagnoses occur in about $2 \%$ of all $x$ rays taken. ${ }^{3}$ However, a large percentage of $x$ rays are normal and it may be more appropriate to calculate an error rate as the percentage of abnormal $x$ rays which are missed, rather than as a percentage of all $x$ rays taken. In a small survey using this technique Vincent $e t$ al found that $35 \%$ of significant $x$ ray abnormalities were missed by junior $A \& E .^{4}$

The purpose of this study was to investigate how well junior doctors in $A \& E$ were able to interpret significant $x$ ray abnormalities and to compare their results with those of senior doctors in $\mathrm{A} \& \mathrm{E}$ and radiology.

\section{Methods}

An $x$ ray quiz was prepared featuring 20 abnormal and 10 normal films. Forty nine $A \& E$ SHOs working in 10 hospitals in the South West Region were set a standardised test during the first three weeks of February 1991. The majority were inexperienced, but 10 doctors had over five months of $A \& E$ experience.

Between 1992 and 1995, 34 senior doctors (senior registrars and consultants) in $A \& E$ and radiology in the South West Region were also tested in the same way.

The only information provided with the quiz was that: (1) all films were taken after a history of trauma; (2) some films were normal; and (3) there may be more than one abnormality on some films.

The 20 abnormal $x$ rays contained 24 abnormalities, and each abnormal $x$ ray had a diagnosis that would affect the patient's management. Doctors were awarded one mark for every abnormality detected, except for a half mark for an ulnar styloid fracture with trans-scaphoid lunate dislocation. The maximum score for the abnormal films was 23.5. The abnormal films showed fractures, dislocations, or other significant injuries which had been missed previously by junior doctors in $A \& E$, but picked up later. The 10 normal films were included for realism so the doctors did not expect an abnormality on each $x$ ray. Six of these had minor normal variants such as an accessory ossicle. The maximum score for the normal films was 10; variants did not have to be specified-simply indicating normality was enough to gain a mark. The quiz was conducted in small groups under examination 
conditions, showing each $x$ ray for half to one minute. At the end of the quiz the correct answers and teaching were given on all the $x$ rays to the junior doctors. Each doctor was given a separate score for their interpretations of the normal and abnormal $x$ rays.

The data were analysed using the nonparametric Wilcoxon rank sum method.

\section{Results}

ERRORS IN INTERPRETING THE 20 ABNORMAL $x$ RAYS

The numbers of junior or senior doctors correctly diagnosing each abnormal $x$ ray are shown in table 1 .

\section{Mean scores of the SHOs}

The mean score for all the SHOs $(n=49)$ was 7.53 out of 23.5 (32\%) with a range of $4-17$ $(17 \%$ to $72 \%)$. The mean score for the 39 inexperienced SHOs was $6.58(28 \%)$ compared to a mean score of $11.25(48 \%)$ for the 10 experienced SHOs. The difference between the two subgroups was statistically highly significant $(P<0.001)$.

\section{Mean scores of the senior doctors}

The mean score for the senior doctors $(n=34)$ was 18.8 out of $23.5(80 \%)$ with range of $13.5-22$ (57\% to $94 \%)$.

The difference between the scores of the junior doctors (SHOs) and of the senior doctors scores was highly significant $(P<$ $0.0001)$.

ERRORS IN INTERPRETING THE 10 NORMAL $x$ RAYS The numbers of junior or senior doctors correctly diagnosing each normal or normal variant $x$ ray is shown in table 2 .

Table 1 Errors in interpreting the abnormal $x$ rays. Number (and percentage) of junior and senior doctors correct for each abnormal $x$ ray (results are listed in increasing order of correctness for the junior doctors)

\begin{tabular}{|c|c|c|}
\hline$x$ Ray abnormality & $\begin{array}{l}\text { No of junior doctors } \\
\text { correct }(n=49) \\
n(\%)\end{array}$ & $\begin{array}{l}\text { No of senior doctors } \\
\text { correct }(n=34) \\
n(\%)\end{array}$ \\
\hline Surgical emphysema of neck (fractured larynx) & $3(6)$ & $28(82)$ \\
\hline Trans-scaphoid lunate dislocation (whole injury) ${ }^{\star}$ & $4(8)$ & $24(71)$ \\
\hline $\begin{array}{l}\text { Fluid level in sphenoidal sinus (basal skull } \\
\text { fracture) }\end{array}$ & $5(10)$ & $29(85)$ \\
\hline $\begin{array}{l}\text { Dislocated base of 5th metacarpal (AP and } \\
\text { oblique views) }\end{array}$ & $6(12)$ & $22(65)$ \\
\hline Perilunar dislocation (1st example) & $6(12)$ & $34(100)$ \\
\hline Odontoid fracture & $7(14)$ & $27(79)$ \\
\hline Radial head dislocation & $7.5(15)$ & $19(56)$ \\
\hline Depressed skull fracture & $8(16)$ & $32(94)$ \\
\hline Sugical emphysema right orbit & $12.5(26)$ & $30(88)$ \\
\hline Gas under diaphragm & $14(29)$ & $24(71)$ \\
\hline Subluxation of cervical spine & $14(29)$ & $25(74)$ \\
\hline Facial fractures and fluid levels (AP views) & $14.5(30)$ & $26(76)$ \\
\hline Frontal skull fracture with aerocele & $15(31)$ & $25(74)$ \\
\hline Tibial plateau fracture & $16(33)$ & $29(85)$ \\
\hline Effusion of elbow & $16.5(34)$ & $34(100)$ \\
\hline Perilunar dislocation (2nd example) & $17(35)$ & $32(94)$ \\
\hline Greenstick fracture distal tibia & $18(37)$ & $29(85)$ \\
\hline Hanging drop sign, left orbital fracture & $20(41)$ & $32(94)$ \\
\hline Comminuted calcaneal fracture & $22.5(46)$ & $34(100)$ \\
\hline Parietal skull fracture & $23(47)$ & $29(95)$ \\
\hline Air in knee joint with soft tissue wound & $23(47)$ & $33(97)$ \\
\hline Lunate dislocation & $24(49)$ & $34(100)$ \\
\hline Anterior dislocated shoulder on chest $\mathrm{x}$ ray & $30(61)$ & $23(68)$ \\
\hline Scaphoid fracture ${ }^{\star}$ & $10(20)$ & $25(74)$ \\
\hline Dislocated lunate & $24(49)$ & $34(100)$ \\
\hline Ulnar styloid fracture ${ }^{\star}$ & $33(64)$ & $21(62)$ \\
\hline
\end{tabular}

^ Components of trans-scaphoid lunate dislocation.

$\mathrm{AP}$, anteroposterior.
Table 2 Errors in interpreting the normal $x$ rays (results are listed in increasing order of correctness for the junior doctors)

\begin{tabular}{lll}
\hline & $\begin{array}{l}\text { No of junior } \\
\text { doctors correct } \\
(n=49) \\
n(\%)\end{array}$ & $\begin{array}{l}\text { No of senior } \\
\text { doctors correct } \\
(n=34) \\
n(\%)\end{array}$ \\
$\begin{array}{lll}\text { Normal or normal variant } x \text { ray } \\
n(\%)\end{array}$ & \\
\hline $\begin{array}{l}\text { Foot with normal epiphysis, } \\
\text { base of 5th metatarsal }\end{array}$ & $10(20)$ & $31(91)$ \\
$\begin{array}{l}\text { Foot (accessory navicular) } \\
\text { Tibia/fibula (growth }\end{array}$ & $11(22)$ & $34(100)$ \\
$\quad$ retardation lines) & $12(24)$ & $29(85)$ \\
$\begin{array}{l}\text { Wrist (fused carpals) } \\
\text { Lateral skull }\end{array}$ & $16(33)$ & $31(91)$ \\
$\begin{array}{l}\text { Lateral cervical spine } \\
\text { Ankle (accessory ossicle) }\end{array}$ & $24(49)$ & $25(74)$ \\
$\begin{array}{l}\text { Chest x ray } \\
\text { Bipartite patella } \\
\text { Axial view of shoulder }\end{array}$ & $27(53)$ & $32(94)$ \\
& $27(55)$ & $30(88)$ \\
\end{tabular}

* 32 junior doctors $(65 \%)$ thought it was a fracture.

Mean scores of the SHOs

The mean score of the SHOs was 4.3 correct out of $10(43 \%$ ) (range $10 \%$ to $60 \%$ ). The 39 inexperienced SHOs scored a mean of 3.9 (39\%) compared with a mean of $5.8(58 \%)$ scored by the 10 more experienced SHOs. The difference between the two subgroups was again statistically significant, although at a lower level than for the abnormal $x$ rays $(\mathrm{P}=$ 0.01 ).

\section{Mean scores of the senior doctors}

The mean score of the seniors was 9.2 out of $10(92 \%)$ (range $70 \%$ to $100 \%$ ), significantly better than the juniors.

\section{Discussion}

A patient who comes to an $A \& E$ department with a depressed skull fracture or a dislocated lunate when a new junior SHO has just started may have a less than even chance of it being correctly diagnosed on $x$ ray. As the mean score for all abnormal $x$ rays was only $32 \%$ it would need an optimist to bet on a correct diagnosis being made. This is worrying.

Senior doctors had a mean score of $80 \%$. These doctors were included to show that the quality of the information and $x$ rays was such that the films were diagnosable to the more experienced eye. Some errors in the senior group also show that no system can be infallible.

Diagnosis depends not just on an $x$ ray, but on clinical features as well. In this study doctors were handicapped by not being given the mechanism of injury or any clinical details other than that the patient had suffered trauma. They also did not have any normal $x$ rays to use as comparisons. If a patient has a very painful or swollen limb and the $x$ ray is thought to be normal, the doctor should ask advice. (This is one of the important rules of A\&E radiology. ${ }^{5}$ ) The senior doctors were similarly handicapped, but scored highly.

The SHOs with over five months of $A \& E$ experience scored $48 \%$. Doctors seem to learn during their time in $\mathrm{A} \& \mathrm{E}$, but the percentage of significant injuries misdiagnosed by these more experienced SHOs is still unacceptable. Normal $x$ rays also proved to be a problem, with only $43 \%$ being correctly diagnosed as normal 
by the junior doctors, compared to $92 \%$ by the seniors.

Many of the injuries shown in this quiz were uncommon or classically difficult for juniors to diagnose. However, all the abnormal $x$ rays had implications for the patient's management. Sixty five $(92 \%)$ of the junior doctors missed the lunate and the perilunate dislocations (compared to less than $10 \%$ in the seniors). This is a commonly missed injury in clinical practice, with previous series finding only $57 \%{ }^{6}$ and $79 \%{ }^{7}$ correctly diagnosed in the first 24 hours. This delayed diagnosis may mean a worse prognosis. ${ }^{6}$

Fractured calcanea are a more common injury and while they are usually easily seen on calcaneal views, the site of tenderness is often not correctly localised and doctors ask for ankle $x$ rays. Although visible on the lateral ankle view, the fracture is usually much less obvious, and $54 \%$ of SHOs missed a severe fracture of the calcaneum with gross disruption of the subtalar joint (seniors were $100 \%$ correct).

Eighty four per cent of juniors failed to diagnose the depressed skull fracture (compared to only $6 \%$ of seniors). In previous series, between $10 \%$ and $60 \%$ of linear skull fractures were missed, ${ }^{89}$ but it is even more important not to miss a compound depressed skull fracture because of potential complications from both sepsis and intracranial injury.

Serious sepsis could also complicate an undiagnosed frontal aerocele and a compound knee joint injury, incorrectly diagnosed by $69 \%$ and $53 \%$ of juniors respectively (compared to $26 \%$ and $3 \%$ of seniors).

Carpometacarpal dislocation, missed by $88 \%$ of juniors (and $35 \%$ of seniors), if diagnosed late would lead to difficulty in reduction and probable long term disability. If clinically or radiologically suspected, a true lateral $x$ ray must also be ordered to elucidate the diagnosis.

The normal $x$ rays introduced for realism also caused problems, with such features as epiphyses and accessory ossicles being frequently misdiagnosed by juniors as fractures. The apophysis at the base of the fifth metatarsal was mistaken for a fracture by $65 \%$ of the junior doctors, which underlines the lack of awareness of normal $x$ ray features.

WHAT CAN BE DONE TO IMPROVE THE SITUATION? Most patients attending $A \& E$ departments are seen by SHOs who are often in their first postregistration post, but it must be recognised that undergraduate training and the preregistration year does not train doctors to work independently in A\&E departments. ${ }^{10}$ Other studies have shown deficiencies in junior $A \& E$ doctors' knowledge or skills of basic life support, ${ }^{12} x$ ray anatomy, ${ }^{13}$ and applied hand anatomy. ${ }^{14} \mathrm{~A} \& \mathrm{E}$ consultants have a responsibility to ensure that patients attending their department are correctly diagnosed and managed. Not only do professional ethics insist that patients are given the best possible care, but increasingly systems to ensure this best care will be demanded by purchasers and by the hospital's insurers and risk managers. ${ }^{15}$ This must involve adequate teaching and support for the junior medical staff, as emphasised by the Royal Colleges. The effect will be that hospitals that do not adequately resource their A\&E departments will have to pay larger insurance subscriptions to the Central Negligence Scheme for Trusts (CNST). ${ }^{16}$ A\&E consultants who feel their departments are underfunded can, with appropriate evidence, discuss these issues with their chief executive or even with the purchasers.

At present, teaching and support commonly consists of an introductory course for junior doctors, regular tutorials, and the provision of a library of textbooks, including new $A \& E$ texts of radiographic anatomy ${ }^{1718}$ and other resources including a library of normal and abnormal $x$ rays. An atlas of normal variants should also be freely available. ${ }^{19}$

Doctors also need support from other specialties and from more senior doctors within A\&E. Increasingly, departments are providing senior and middle grade cover within the department for, if possible, 16 or more hours per day. The national shortage of junior doctors is leading to some departments appointing more permanent middle grade staff. ${ }^{20}$ The often inadequate middle grade and senior staffing levels, and their importance, has been commented on by the National Audit Office both in 1992 and $1996 . .^{21} 22$

The missed diagnosis of $x$ rays can be kept to a minimum by a "hot" reporting system, ${ }^{3}$ but where this is not available, radiographers can improve diagnostic accuracy by a "red spot" system to mark abnormal $x$ rays. ${ }^{23}$ As a back up, all A\&E $x$ rays should be reported by a radiologist within 24 hours. (The Royal College of Radiologists recommend that in general all $x$ rays should be reported within three working days, but this upper limit would not be ideal for some of the missed injuries in $A \& E$, especially over weekends and public holidays.) Such fail-safe systems must be subjected to regular audit or review along with the missed injuries for feedback to the doctors. Senior A\&E doctors and radiologists are only human and if there is any reason to doubt their $x$ ray report, the patient or their $x$ rays (or both) must be reviewed as a further safety measure. ${ }^{5}$

While this back up for SHOs is essential, it must be recognised that one of the hallmarks of inexperience is that doctors may not know when to ask for advice. In other specialties (for example, radiology, pathology, anaesthetics) junior medical staff have to receive training, and may be examined on their abilities before being allowed to treat patients or make diagnostic decisions. They then work under close supervision before being allowed to work independently. Although not all pitfalls can or should be covered, a scheme to detect abnormalities and provide safe management can be taught. $^{5}$ In $\mathrm{A} \& \mathrm{E}$, doctors should receive specific training in the interpretation of $x$ rays and should be tested on their ability before being allowed to work independently. Such a system may involved SHOs spending their first month in post receiving formal teaching and 
working under close one to one supervision before being allowed to practice under the looser supervision which occurs at present. Such formal training would benefit not only $\mathrm{A} \& \mathrm{E}$ departments but also the other specialties, including general practice, in which our SHOs subsequently work. This will necessitate a reorganisation of the staffing and funding of accident and emergency departments which, although costly, will be necessary to ensure adequate patient care.

\section{CONCLUSIONS}

This study shows that SHOs are not safe to treat and discharge patients on their own. It is vital that $A \& E$ departments have adequate education, staffing levels, audit, and fail-safe mechanisms to avoid misdiagnoses and minimise complaints.

The staffing of $A \& E$ departments needs to be altered so that most patients are seen by experienced and trained doctors, mainly to ensure adequate care, but also to make for better risk management. $\mathrm{A} \& \mathrm{E}$ is a good training ground for doctors wanting to work in general practice and other specialties as well as $A \& E$, but these inexperienced doctors must be closely supervised.

We would like to thank Dr Alan Hedges and Mr Basil Norbury for statistical help, the junior and senior doctors in the South West Region who kindly participated, and Julie Hopper for word processing.

1 Guly HR. Missed diagnoses in an accident and emergency department. Injury 1984:15:403.

2 Tachakra S, Beckett $M$. Why do casualty officers miss radiological abnormalities? J R Coll Surg Edinb 1985;30:311logical abnormalities? J R Coll Surg Edinb 1985;30:31113.

DeLacey G, Barker A, Harper J, Wignall B. An assessmen of the clinical effects of reporting accident and emergency radiographs. Br J Radiol 1980;53:304-9.
4 Vincent CA, Driscoll PA, Audley RJ, Grant DS. Accuracy of detection of radiographic abnormalities by junior doctors. Arch Emerg Med 1988;5:101-9.

5 Touquet $R$, Driscoll $P$, Nicholson $D$. Teaching in accident and emergency medicine: 10 commandments of accident and emergency radiology. BMJ 1995;310:642-5.

6 Rawlings I. The management of dislocations of the carpal lunate. Injury 1981;12:310-30.

7 Ponting A, Lamb D, Noble J, Haw C. Dislocations of the lunate with and without fracture of the scaphoid. J Bone Joint Surg ? 1984;66-B:391-5.

8 Gorman D. The utility of post-traumatic skull X-rays. Arch Emerg Med 1987;4:141-50.

9 Gibson T. Skull X-rays in minor head injury: a review of their use and interpretation by casualty officers. Scot Med J 1983;28:132-7.

10 Yates DW, Wakeford R. The training of junior doctors for accident and emergency work: a case for urgent treatment? Injury $1985 ; 14: 456-60$.

11 Morris F, Cope A, Hawes S. Training in accident and emergency: views of senior house officers. BMJ 1990;300: $165-6$.

12 Skinner DV, Camm AJ, Miles S. CPR skills of preregistration house officers. BMJ 1985;290:1549.

13 Gardener G. A study of the knowledge of radiological anatomy of senior house officers in accident and emergency medicine. Arch Emerg Med 1989;6:51-5.

14 Murphy NM, Olney DB. Applied hand anatomy: its importance in accident and emergency. Arch Emerg Med 1992;9:14-18.

15 Powers S, Harris N, eds. Medical negligence, 2nd ed. Oxford: Butterworths, 1994:24.4-24.19.

16 Vincent C. Clinical risk management (A\&E section). BMJ Publishing Group, 1995.

17 Raby N, Berman L, deLacey G. Accident and emergency radiology - a survival guide. Philadelphia: WB Saunders, 1995.

18 Nicholson DA, Driscoll P. $A B C$ of emergency radiology. London: BMJ Publishing Group, 1995.

19 Keats T. Atlas of normal roentgen variants that may simulate disease, 4th ed. Philadelphia: Year Book Medical Publishers, 1996.

20 Stewart IP. Staffing of accident and emergency department. J Accid Emerg Med 1996;13:412-4.

21 National Audit Office. Report by the Controller and Auditor General. London: HMSO, 1992.

22 The Audit Commission. By accident or design? Improving $A E O E$ services in England and Wales. London: The Audit Commission, 1996.

23 Berman L, deLacey G, Twomey E, Twomey B, Welch T, Eban R. Reducing errors in the accident and emergency department: a simple method using radiographers. BMJ $1985 ; 290: 421-2$ 